\title{
Sobre a Mulher Escrava no Rio Grande do Sul
}

\author{
Margaret M. Bakos*
}

A versão original desta comunicação foi elaborada a partir de um convite da Secretaria Municipal de Cultura, na pessoa do organizador do Curso, professor Mário Maestri, para falar sobre a mulher negra escrava no Rio Grande do Sul.

O tema proposto instigou um questionamento inicial: em quais aspectos o escravismo seria diferente para o homem e para a mulher?

As relações sociais escravistas coisificam os indivíduos, impedindo-os de se movimentarem livremente, embotando e inibindo os seus sentimentos e instintos. Homens e mulheres, na escravidảo, tornam-se seres de propriedade de outrem, com vontade sujeita à autoridade do dono e seu trabalho ou serviços são obtidos através da coerção.

Nesta linha de raciocínio, torna-se difícil delinear e conseqüentemente falar sobre a situação específica da mulher no cativeiro, pois a base estrutural da sua existência não está em ser fêmea. Está em ser escrava.

Será impossível identificarmos, a nível estrutural, uma posição masculina ou feminina na escravidão?

Toda diferença entre o papel do homem e da mulher no escravismo será sempre conjuntural e relacionada ou com a atividade que o negro exerce, ou com o momento histórico que vivencia. Homens e mulheres negros escravizados no Rio Grande do Sul, ao longo de dois séculos,

\footnotetext{
* Autora do livro RS: escravismo e abolição, Porto Alegre, Mercado Aberto, 1982. Professora do curso de Graduaçăo e Pós-Graduaçăo de História da Universidade Federal do Rio Grande do Sul.
} 
sofreram, capitularam e reagiram ao cativeiro através de ações, mais ou menos cooperativas ou agressivas, independentemente do seu sexo, relacionadas basicamente com as variáveis apontadas.

A minha proposta nesta apresentação não 6 , portanto, estabelecer um inventário, no meu entender forçadíssimo, das diferenças entre homens e mulheres escravizados. A tendência, nesta perspectiva, é a de situar aos primeiros como heróis em potencial, em constante enfrentamento com o jugo senhoril, caracterizando as segundas como vítimas duplas, da passividade inerente ao sexo e da violência dos senhores, conforme as retrataram inumeras vezes os historiadores positivistas. Impõe-se uma nova visão, pois não é assim que vejo as mulheres escravas, genericamente falando. Acredito que entre os escravos encontramos gente assumida, sensivel e combativa, mas também homens e mulheres entregues aos desmandos dos senhores, interna e profundamente autocoisificados, independente do seu sexo.

Ao tentar resgatar aspectos do engajamento feminino na luta contra a opressão, analiso três momentos definidos na relação escravista:

\section{I - No Trabalho}

A idéia desta abordagem originou-se a partir de um debate que se estabeleceu, ao final de uma palestra que proferi, em 1988, em Porto Alegre. Eu falara sobre a mulher escrava na capital do Estado e, para ilustrar o encontro, li alguns anúncios, publicados em jornais do século passado, que ou solicitavam ou ofereciam escravas negras para serviços domésticos. Muitos dos anúncios solicitavam que a serviçal fosse realmente habilitada como cozinheira. Neste momento, uma das assistentes, estranhando o fato, espontaneamente, comentou que sempre pensara que as negras fossem "naturalmente" boas cozinheiras e competentes domésticas, de um modo geral.

O questionamento que me ocorreu em torno desta intervenção foi sobre as origens históricas deste pensamento que, possivelmente, ainda se haja presente na cosmovisão de muitos gaúchos.

O escravo negro começou a ser introduzido no Rio Grande do Sul nos finais do século XVIII, com vistas a atender as necessidades das charqueadas sulinas. Aos poucos começou-se a utilizar o escravo para as atividades de peonagem e agricultura. Nestes primeiros tempos, o que mais importava era possuir um escravo negro, fisicamente apto para estas 
atividades. Foi com o desenvolvimento dos centros urbanos, a partir principalmente da primeira metade do século XIX, que a mulher escrava passou a ser uma peça cobiçada e fundamental para a sociedade gaúcha. Uma das poucas estatísticas que temos, e que diferencia a presença numérica dos escravos homens e mulheres, data de 1859. Ela arrola 25 cidades sedes de municípios, salientando-se como localidades que mais possuem escravos as seguintes:

\section{Localidade}

Porto Alegre

Pelotas

Jaguarão

Rio Grande

Cruz Alta

\section{Homens}

4.556

3.095

2.929

2.503

2.315
Mulheres

3.861

1.693

2.127

1.866

1.704

Vemos assim que nestas localidades urbanas havia uma presença de escravos negros, homens e mulheres, significativa, o que revela a necessidade de ambos para diferentes trabalhos.

Uma análise do seu valor de compra, no mesmo ano (1859), nos permite resgatar que a diferença de preço também não era muito significativa:

Preços de escravos negros no Rio Grande do Sul em 1859

Para a agricultura

Homens

Mulheres

$1.250 \$ 000$

$1.150 \$ 000$

Para serviços domésticos

Homens

Mulheres

$1.400 \$ 000$

$1.250 \$ 000$

Se as mulheres negras eram numericamente importantes e economicamente valorizadas, resta perguntar para que atividades eram destinadas.

Talvez uma das melhores fontes para obter esta resposta seja justamente a análise dos anúncios de jornais. O O Diário de Porto Alegre, de 1827, é uma das mais antigas fontes para este tema e aponta cerca de 21 atividades para as quais o trabalho escravo era requisitado, em Porto 
Alegre. As mulheres eram procuradas para trabalharem como costureiras, doceiras, lavadeiras, engomadeiras, cozinheiras, amas de leite, arrumadeiras, fiadeiras e refinadoras de açúcar. Com vistas a responder ao questionamento inicial, é importante chamar atenção para alguns ângulos sob os quais esta série de anúncios pode ser analisada:

a) A mulher escrava foi utilizada como mão-de-obra em dezenas de atividades designadas, para fins públicos, como domésticas, ligando-se a estas remotas origens uma série de preconceitos, que pode ser resumida no ditado popular machista e racista que diz ter a mulher negra um lugar garantido: "no palco, na cama e na cozinha, sem fazer concurso público e com estabilidade assegurada". (O Tição, Ano 1, out. 80, p.3)

b) O que chama a atenção nesta coletânea de anúncios, em número de 46, é que 13 relacionam-se com a atividade de fazer comida. Assim, não fica difícil entender por que foi tão profundamente internalizada, nas pessoas, a relação escrava negra cozinha. A ponto de alguém, no ano de 1988, ainda considerar que todas as negras eram em princípio boas cozinheiras. Entretanto, é justamente aí que se pode buscar os aspectos da resistência \coerção ao trabalho, que, em última análise, assinalam a semelhança entre homem \mulher, na escravidão. Explicando melhor, tanto faz, num regime de trabalho compulsório, se se é escravo \escrava; a diferença entre um e outra não se faz por aí. Ser senhor \senhora isto é o que importa. Os pólos da relação escravista, independente do seu sexo, dominam ou ao chicote ou apenas ao seu próprio corpo. Sob esta ótica repensei os dados e, em base às fontes que enfatizavam a preparação para o trabalho doméstico, que se exigia das escravas, tentei recuperar o processo de ensino \aprendizagem que muitas negras devem ter passado entre o fogão e a despensa, desesperadas por não saberem o que fazer com panelas e víveres, que não conheciam, dos quais não gostavam e que eram obrigadas a cheirar, cozinhar, servir e comer. O chicote, a senzala e o terror foram certamente os mestres mais eficientes do período e os responsáveis pelo nossa preconceituosa idéia de que todas as negras são "naturalmente" boas cozinheiras. Até este momento, não se tem uma análise exaustiva da documentação que evidencie tais conclusões. Entretanto, isto não justifica que se aceite a História que forma estereótipos, tomando como verdadeiras afirmações geradas pela tradição oral e pela leitura simplista dos documentos, sem críticas e questionamentos. A cozinheira, a copeira e a babá permitiram que a 
senhora se alimentasse e que a sua família se perfumasse, se banhasse, namorasse nas janelas e saraus e procriasse novas sinhazinhas. É através da análise do sistema escravista que se evidencia a formação, a ferro e fogo, das habilidades "naturais" da mulher negra, cuja excelência somente será questionada quando a mulher imigrante empobrecida vier a disputar com a negra o trabalho doméstico, principalmente o urbano. Entretanto, até os dias de hoje, ainda são comuns os ditados populares, que a tradição oral preservou, e que nos fazem olhar com simpatia ou resistência seres humanos, com relação à sua capacidade do trabalho. Quem nunca ouviu: "Negra de canela fina é que é boa trabalhadeira!"?

\section{II - Na resistência}

Considero como resistência toda reação de inconformidade do negro quanto à escravidão. Isto inclui desde tentativas de fugas, formação de quilombos, agressões contra senhores e feitores, assassinato dos próprios filhos, suicídios até o "corpo mole" inocente e preguiçoso, o "dengue" doce que alicia e comove, influenciando o humor dos circundantes. Esta abrangência se justifica pela impossibilidade de saber, atualmente, se o sorriso de submissão não teria sido tão falso quanto o famoso e decantado riso do palhaço de circo.

Não há nenhum trabalho sistemático sobre fugas, quilombos e criminalidade escrava no Rio Grande do Sul que permita uma comparação estatística entre o número de mulheres e homens que fugiram. Este estudo seria difícil pelas inúmeras variáveis que teriam de ser levadas em conta. Resta, pois, exemplificar a resistência feminina, relendo fontes, até agora, utilizadas para generalizações em torno da resistência escrava.

Um dos documentos mais antigos sobre a revolta dos escravos no Rio Grande do Sul refere-se a um episódio ocorrido na Real Feitoria do Linho cânhamo, em 2 de agosto de 1822. Nesta ocasião, houve uma denúncia de que havia pretos desta fazenda que costumavam roubar na vizinhança, sendo destacado um grupo de soldados para prendê-los, porém eles nada puderam fazer, pois os negros não se entregaram à prisão e, instigados por suas mulheres, que gritavam para que eles matassem os soldados, entraram nas suas moradias, armaram-se e atacaram a guarda que terminou voltando para os seus quartéis. (Feitoria Nacional do Linho Cânhamo, lata 300 - AHRGS.) 
Neste episódio, resgata-se a negra que grita e instiga, que nada teme na luta contra o branco armado; mas não é preciso ficar apenas nesta inferência, podemos ver, além disso, a companheira de uma luta maior contra a escravidão, que se expressa quando ela incita uma atitude agressiva. Leitura nesta direção pode ser feita sobre o significado da participação feminina na história do quilombismo gaúcho.

No quilombo do Negro Lucas, em Rio Grande, em 1833, participavam seis homens e quatro mulheres, que viviam em uma casa grande, onde preparavam sebo, graxa e charque para vender. Nos quilombos de Rio Pardo foram indiciadas sete mulheres que, juntamente com treze homens, viviam de roubos nas plantações das vizinhanças.

Para viver em um quilombo era, primeiramente, no mínimo, necessário que o escravo enfrentasse a problemática de sua fuga, que era mais ou menos difícil, dependendo das atividades que ele exercia, do grau de vigilância que sofria e, naturalmente, da sua constituição física, que devia ser a melhor possível, pois que ele deveria percorrer longos percursos, alimentar-se esporadicamente, quando encontrasse o que comer, e sofrer de muita ansiedade com a ameaça permanente de enfrentamento aberto com autoridades constituídas - como o famigerado capitão de mato - até chegar a um refúgio. Essa foi também a saga da mulher quilombola, naturalmente no caso de ela ter ido espontaneamente para o quilombo. Em tal caso, há necessidade de esboçar um quadro mais realista de um ato de resistência? Até mesmo os representantes do sistema, com melhores vestimentas, montarias e esquemas de sobrevivência, amargavam na incumbência de perseguir os negros fugidos, como é sobejamente ilustrado na documentação oficial. Então, porque não valorizarmos ao máximo a ação quilombola como um alto de extrema coragem e valentia? Se eles não tinham o objetivo de transformar a sociedade, como afirma Gorender, pelo menos, a hostilizavam. Se buscavam recompor a sociedade tribal africana, segundo pensamento do mesmo autor, homens e mulheres partilhavam do mesmo desejo. Naturezas femininas e masculinas, sob a escravidão, interagiam com o medo, planejavam atingir o estado utópico, o nirvana de qualquer cativo, em qualquer época histórica: a liberdade!

Há alguns, verdadeiramente não muitos, relatos de casos em que as escravas resistiram ao assédio de negros, seus companheiros de cativeiro, como o incidente que culminou no assassinato da esposa de um feitor 
negro - em fazenda do Alegrete - porque ela não cedeu a um escravo que queria forçá-la "para fins libidinosos". (Relatório do Presidente da Província do Rio Grande do Sul João Capistrano Miranda Castro, 1848, Porto Alegre, Tipografia Porto Alegrense.) $\mathrm{O}$ ato que ficou registrado no processo crime aberto contra o assassino nos permite, agora, rever a vítima no seu comportamento corajoso, que a levou à morte, desmistificando a idéia romântica da mulher por índole submissa.

Em uma pesquisa sobre os cárceres de Porto Alegre, na primeira metade do século XIX, encontrei mulheres negras aprisionadas ou pelo simples arbítrio de seus senhores ou por terem cometido crimes. (Bakos, 1982: 209-221.) Apenas na cadeia de Justiça, foram encontradas 13 escravas negras presas.

A seguir, discrimino dois crimes de que escravas foram acusadas, no Rio Grande do Sul, procurando com isto apenas exemplificar o pensamento de que as mulheres reagiram, como os homens, à escravidão, agredindo os seus senhores com as armas de que dispunham. Julgo importante apontar a existência de centenas de processos crimes envolvendo negras escravas ou livres, nos arquivos públicos do Rio Grande do Sul, os quais ainda não foram analisados ou o foram precariamente. Importantes referenciais sobre o significado do ato de agressão da cativa podem e devem ser inferidos das leituras destes processos, que se constituem, fora de dúvida, na mais rica fonte disponível para a compreensão das atitudes do escravo de ambos os sexos, resgatando para a atualidade elementos constitucionais das naturezas feminina e masculina.

$\begin{array}{lccc}\text { Crime } & \text { Dados do Escravo } & \text { Ano } & \text { Motivo } \\ \begin{array}{l}\text { - Matou a } \\ \text { senhora com } \\ \text { o machado }\end{array} & \text { Felisberta } & \begin{array}{c}1821 \\ \text { Sastigada }\end{array} \\ \begin{array}{l}\text { - Colocou } \\ \text { veneno na } \\ \text { comida do sr. }\end{array} & \text { Florinda } & 1828 & \text { sem motivo } \\ \text { e familia } & & \text { P. Alegre } & \text { queria só } \\ \text { ameaçar }\end{array}$


As respostas de Felisberta e Florinda são muito eloqüentes: "agredi, porque fui agredida sem motivo", "agredi, mas não queria machucar, só queria assustar". Poderíamos analisar dezenas de processos como estes, mas não estão aí resumidos, apenas nestes dois, os princípios básicos do ser humano no seu relacionamento em sociedade? Para isto, não foi necessário que as negras saissem às ruas, fazendo parte de grupos armados, praticando violências planejadas. As cenas protagonizadas por Felisberta e Florinda aconteceram entre as paredes de casas, onde viviam pessoas ordeiras. Naturalmente ali se reproduziam as relações de trabalho escravistas, com muita crueza, pois na privacidade do espaço íntimo, as autoridades são mais presentes, despóticas, viciosas, impunes. Entretanto, no esquema rotineiro, uma 'coisa' saiu do seu lugar. Tanto faz se era uma 'coisa' masculina ou feminina. Interessa que ela saiu; com isso, mexeu com a ordem, mostrou que não era só 'coisa', era gente e igual a toda gente: homem ou mulher. Felisberta e Florinda, protagonistas da mudança, nossos objetos de análise, conseguiram, à época, com suas atitudes, saírem do espaço privado da casa. Se elas queriam sair, nunca saberemos. Mas o fato aí está para ser analisado: elas foram conduzidas a um fórum, foram interrogadas, ouvidas. Suas vozes ficaram registradas nos autos dos processos, chegaram até nós. Impossível saber quais os sofrimentos físicos e mentais, as torturas, que elas sofreram na passagem de um espaço para o outro, pois o cenário maior dos quadros continuava a ser o escravismo. Havia dor \chicote, fedor \sujeira, em todos os locais destinados aos negros. Nos autos dos processos, ficou registrado: um machado foi desviado, da lenha para a senhora, que na visão da escrava, foi uma juíza injusta dos seus atos. Um punhado de veneno para ratos foi parar nas baixelas senhoris. Tudo por mãos de negras, tudo para exteriorizar sentimentos de raiva, medo, ódio: pura emoção. Com esta leitura, não pretendo desculpar ou minorar um ato agressivo, muito menos justificar o emprego da violência nas relações humanas. Ao contrário, vejo a capacidade de agredir física ou mentalmente ao seu semelhante como a pior das características humanas. Por esta razão, por ser constitutiva e essencial na luta pela vida, a violência pode ser reduzida a um viés de análise histórica. Entender o porquê da violência, na visão de quem a pratica e a sofre, pode ser mais um meio para o historiador resgatar o sentido do jogo social pela vida. 


\section{III - No engajamento social}

Uma outra instância em que a mulher escrava pode ser analisada é no seu engajamento na sociedade. Um bom exemplo é a sua participação na Confraria de Nossa Senhora do Rosário, fundada em Porto Alegre, em 1786, que tinha como principal objetivo a educação religiosa e a benemerência, mas que também funcionava como um local de agrupamento dos negros e, muitas vezes, para conspirações ou ataques espontâneos à ordem constituída. Assim, embora institucionalizadas, as confrarias eram muitas vezes perseguidas e as suas procissões e festas proibidas e os seus membros visados pela polícia local. Mesmo assim, a presença da mulher negra livre ou escrava era uma constante, prevista, inclusive no Regimento da Confraria, mas da qual ela participava com todo o seu engajamento, conspirando também, como o homem...

\section{Conclusão}

A submissão da mulher foi uma invenção de um mundo comandado por homens que também inventaram a escravidão. (Mott, 1988: 21) Mas, subjacente a estes garrotes ideológicos e concretos, a mulher, constitucionalmente, tinh a forças e meios para resistir, com garra e oportunismo, tal como o homem. Por isto ela não merece ser registrada historicamente como dupla vítima do sistema. O que realmente lhe é devido é uma revalorização de seus atos, concedendo-lhes a devida dimensão e mérito. Isto apenas será possível se entendermos que a mulher escrava podia resistir ao jugo senhoril, de uma forma diferente que o homem. Se aceitarmos como resistência coisas do cotidiano, muito simples, como a indolência no trabalho, a dificuldade no aprendizado de novas tarefas, o tratamento "dengoso" que dispensava ao senhor e à sua família. Ao lado destas atitudes que a livravam dos excessos de trabalho e dos castigos, a escrava negra, como vimos, também agrediu a sociedade escravista: fugiu, furtou, matou, como todas no país. Foram protagonistas da História da escravidão negra no Brasil, vítimas, mas também agressores, todos os seres humanos vindos da África e os seus descendentes, independentemente do seu sexo: impossível fazer um recorte e falar sobre a mulher escrava especificamente, sem desenvolver uma argumentação machista! 


\section{Bibliografia citada}

BAKOS, M. Os escravos negros nos cárceres de Porto Alegre: Sugestões de uma documentação do século XIX. In Revista de Estudos llbero Americanos. PUCRS, 8(2):209-23, 1982.

- RS: Escravismo e Abolição. Porto Alegre, Mercado Aberto, 1982.

CARDOSO, C. Escravo ou Camponês? São Paulo, Brasiliense, 1987.

GIACOMINI, S. Mulher e Escrava. Rio de Janeiro, Vozes, 1988.

GORENDER, J. Questionamento sobre a teoria econômica do escravismo colonial. In Estudos Econômicos. 13(1):7-41, 1983.

MAESTRI, M.J. O Escravo no Rio Grande do Sul. Caxias do Sul, Escola Superior São Lourenço dos Brindes, 1984.

MOTT, Mário Lúcio. Submissão e Resistência. São Paulo, Contexto, 1988.

MOTTA, F. Crime e rebeldia escrava no Rio Grande do Sul (1820-1845). Trabalho de conclusão de bacharelado. UFRGS, jan. 1985. p.47. [Mimeo]

REIS, J.R. \& SILVA, E. Negociação e Conflito. Rio de Janeiro, Cia. das Letras, 1989.

SCHWARTZ, S. Mocambos, quilombos e palmares: a resistência escrava no Brasil Colonial. In Estudos Econômicos. 17(especial), 1987. 